\title{
Imagining rotation of objects: Comment on Shepard and Metzler
}

\author{
NICHOLAS F. SKINNER and ROGER STRETCH \\ University of Saskatchewan, Saskatoon, Saskatchewan, Canada
}

\begin{abstract}
In contrast to previous research with human subjects, response latencies for imagining depth rotations were longer than (rather than equal to) latencies for picture-plane rotations of three-dimensional objects.
\end{abstract}

In a study of perception of dimensionality, Shepard and Metzler (1971) concluded that "the time required to recognize that two perspective drawings portray objects of the same three-dimensional shape is found to be (a) a linearly increasing function of the angular difference in the portrayed orientations of the two objects and (b) no shorter for differences corresponding simply to a rigid rotation of one of the two-dimensional drawings in its own picture plane than for differences corresponding simply to a rotation of the three-dimensional object in depth (p. 701)." To support these findings, they noted comments by the participants to the effect that "mental rotation" of the simultaneously paired perspective drawings could be performed with equal facility through two or three dimensions. The present research evaluated not only Shepard and Metzler's (1971) results but also the accuracy of their subjects' self-reports.

\section{METHOD}

\section{Apparatus and Materials}

Based on the earlier study, stimuli consisted of photographic slides of computer-derived perspective drawings of a variety of purposely unfamiliar and nonmeaningful "nonsense objects," consisting "of ten solid cubes attached face-to-face to form a rigid armlike structure with exactly three right-angled 'elbows' (Shepard \& Metzler, 1971, p. 702)."

Using automated matching-to-sample (MTS) equipment, containing manually depressable panels illuminated by rear projection and housed in a sound- and light-attenuated $6 \times 6 \times 8 \mathrm{~m}$ chamber, it was possible to present comparison stimuli (COs) which differed in orientation from the standard stimulus (ST) by each possible angle, in 20-deg steps, from $0 \mathrm{deg}$ to $180 \mathrm{deg}$. In each trial, one comparison stimulus $\left(\mathrm{CO}_{2}\right)$ represented a rotation of the ST through two dimensions (i.e., in the picture plane) and the other $\left(\mathrm{CO}_{3}\right)$ corresponded to a depth (i.e., three-dimensional) reorientation of the ST. In "marker trials," both $\mathrm{CO}_{2}$ and $\mathrm{CO}_{3}$ were

This study was conducted while the first author was a National Research Council Postdoctoral Fellow at the University of Saskatchewan, Saskatoon, Saskatchewan, Canada. Funding was proviced in part by National Research Council Grant No. /.7898 to the second author, now Director of the Behavioural Pharmacology Research Unit, Faculty of Psychology, University of Ottawa, Ottawa, Ontario, Canada KIN 6N5. Reprints may be obtained from the first author, now at King's College, London, Ontario, Canada N6A $2 \mathrm{M} 3$.

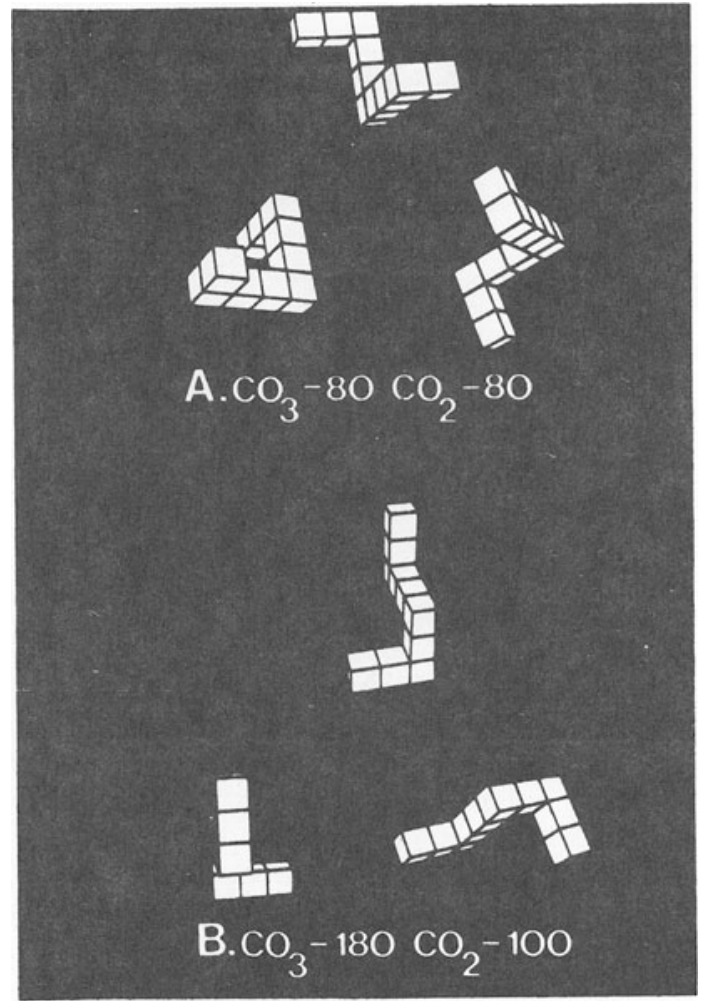

Figure 1. Above. Marker trial: $\mathrm{CO}_{3}$ (lower left) represents top object (ST) rotated 80 deg in depth (i.e., three-dimensionally) and clockwise; $\mathrm{CO}_{2}$ (lower right) represents ST rotated 80 deg clockwise in the picture plane (i.e., two-dimensionally). Below. Nonmarker trial: $\mathrm{CO}_{3}$ (lower left) represents ST rotated 180 deg in depth; $\mathrm{CO}_{2}$ (bower right) represents ST rotated 100 deg anticlockwise in the picture plane. Left-right positioning of COs was equalized in a random order.

rotated equally, while for the remaining trials the magnitude of rotation within CO pairs differed from $20 \mathrm{deg}$ to $160 \mathrm{deg}$ (see Figure 1).

\section{Subjects and Procedure}

Following a series of simultaneous MTS practice trials (cf. Cumming \& Berryman, 1965, p. 290), 32 undergraduate subjects (mean age 19.87 years, range $17-25$ years) individually completed 36 trials (including nine marker trials) according to these instructions: "The bottom objects $\left[\mathrm{CO}_{2}\right.$ and $\left.\mathrm{CO}_{3}\right]$ represent the top object [ST] rotated into different positions in space. Your task is to indicate (by pressing the appropriate panel) which of the two lower objects is closer to the spatial position of the top object. In other 
Table 1

Mean Response Latency and Number of Two- and Three-Dimensional Comparison Stimuli Chosen on Representative Marker Trials

\begin{tabular}{|c|c|c|c|c|c|c|}
\hline $\begin{array}{c}\text { Marker } \\
\text { Trial }\end{array}$ & $\begin{array}{c}\mathrm{ST}-\mathrm{CO}_{2} \\
\text { Difference } \\
\text { (deg) }\end{array}$ & $\begin{array}{c}\mathrm{ST}-\mathrm{CO}_{3} \\
\text { Difference } \\
\text { (deg) }\end{array}$ & $\begin{array}{l}\text { Number of } \\
\mathrm{CO}_{2} \text { Choices* }\end{array}$ & $\begin{array}{l}\text { Response Latency } \\
\text { for } \mathrm{CO}_{2} \text { Choices } \\
\text { (sec) }\end{array}$ & $\begin{array}{c}\text { Number of } \\
\mathrm{CO}_{3} \text { Choices* }\end{array}$ & $\begin{array}{c}\text { Response Latency } \\
\text { for } \mathrm{CO}_{3} \text { Choices } \\
(\mathrm{sec})\end{array}$ \\
\hline 1 & 20 & 20 & 20 & 4.91 & 12 & 5.29 \\
\hline 2 & 60 & 60 & 25 & 6.22 & 7 & 8.60 \\
\hline 3 & 80 & 80 & 26 & 7.67 & 6 & 9.11 \\
\hline 4 & 100 & 100 & 28 & 8.21 & 4 & 10.56 \\
\hline 5 & 140 & 140 & 28 & 8.02 & 4 & 10.16 \\
\hline 6 & 180 & 180 & 22 & 7.65 & 10 & 8.49 \\
\hline
\end{tabular}

*With 32 subjects, on each trial the total of $\mathrm{CO}_{2}$ and $\mathrm{CO}_{3}$ choices combined was 32.

words, you are to decide which of the lower objects has been rotated away from the position of the top object by the lesser amount."

\section{RESULTS AND DISCUSSION}

Examination of $\mathrm{CO}$ choice data revealed that for both sexes the combination of an increase in the magnitude of rotation of the COs away from the ST and a decrease in intra- $\mathrm{CO}$ rotation differences was associated with a: (a) concomitant lengthening of response latency and (b) marked increment in the number of $\mathrm{CO}_{2}$ choices. As shown in Table 1, these trends were most pronounced on marker trials (i.e., when intra- $\mathrm{CO}$ differences were $0 \mathrm{deg}$ ), particularly in the intermediate range of ST-CO differences (60-140 deg).

While procedural dissimilarities admittedly preclude strict comparison, these results can nonetheless be seen to run contrary to the findings of Shepard and Metzler (1971). That is, when asked to scrutinize the spatial orientations of a three-dimensional test object and a pair of simultaneously presented versions of that test object rotated equally through two and three dimensions, respectively, subjects in the present study chose the two-dimensional rotation as being "closer" to the position of the test object by a ratio of more than 3:1. Without exception, furthermore, response latency was longer (range .38-2.35 sec, mean $.83 \mathrm{sec}$ ) for marker trials on which $\mathrm{CO}_{3}$ rather than $\mathrm{CO}_{2}$ was chosen. Interestingly, however, although most subjects reported that they had quickly discovered the nature of the difference between COs, they expressed surprise when informed during postsession interviews that their choices had been predominantly two-dimensional. It is possible that implicit in this surprise is the judgment made by subjects in Shepard and Metzler's (1971) study to the effect that "since they perceived the two-dimensional pictures as objects in three-dimensional space they could imagine the rotation around whichever axis was required with equal ease (p. 702)."

Nonetheless, the quantitative data summarized here strongly suggest that, subject's opinions notwithstanding, "mental rotation" through three dimensions is a more complex cognitive exercise than imagining two-dimensional rotation. Ongoing followup studies have been designed to assess the generalizability of this finding to: (a) a monocular situation, and (b) tactile determination of dimensionality of object rotation by both blind and sighted subjects.

\section{REFERENCES}

Cumming, W. W., \& Berryman, R. The complex discriminated operant: Studies of matching-to-sample and related problems. In D. I. Mostofsky (Ed.), Stimulus generalization. Stanford: Stanford University Press, 1965. Pp. 284-330.

ShePARd, R. N., \& Metzler, J. Mental rotation of three-dimensional objects. Science, 1971, 171, 701-703.

(Received for publication October 22, 1975.) 